Article

\title{
Perceived Acceptability of Implementing Marker-Assisted Selection in the Forests of British Columbia
}

\author{
Chelsea Nilausen ${ }^{1, *}$, Nancy Gélinas ${ }^{2}$ and Gary Bull ${ }^{1}$ \\ 1 Department of Forest Resources Management, Forest Sciences Centre, 2424 Main Mall, \\ The University of British Columbia, Vancouver, BC V6T 1Z4, Canada; gary.bull@ubc.ca \\ 2 Département des Sciences du Bois et de la Forêt, Faculté de Foresterie, de Géographie et de Géomatique, \\ 2145-A Pavillon Abitibi-Price, 2405 rue de la Terrasse, Université Laval, Québec, QC G1V0A6, Canada; \\ nancy.gelinas@sbf.ulaval.ca \\ * Correspondence: chelsea.nilausen@ubc.ca; Tel.: +1-604-822-1553
}

Academic Editors: John MacKay and Stephen P. DiFazio

Received: 11 October 2016; Accepted: 12 November 2016; Published: 18 November 2016

\begin{abstract}
The forest sector in British Columbia (BC) has faced a number of challenges over the past decade. In response to some of those challenges, the government has invested in forest genomic tools. Marker-assisted selection (MAS) is a biotechnological tool that flags desired traits on the genome. This tool may assist tree breeders with the early selection of preferred genotypes, reducing the breeding cycle and more accurately and efficiently selecting for improved qualities. However, there is a poor understanding of the perceived acceptability of implementing MAS. Semi-structured interviews and a questionnaire were employed across participants categorized into four groups. It was found that government and industry participants held positive perceptions towards MAS, supporting its use and continued research in $\mathrm{BC}$, and identifying its benefits in forest regeneration and to tree breeders. Environmental non-governmental organizations (ENGOs) and First Nations attitudes lay between neutral and negative. Concerns were most strongly focused on environmental impacts, ecosystem degradation, and reduced genetic diversity, while identified benefits were specific to tree breeders and improved tree resiliency. It was concluded that before MAS can be successfully implemented, an appropriate setting must first be established through improved knowledge of biotechnology and its applications, well-defined policies, and strengthened engagement and consultation with First Nations.
\end{abstract}

Keywords: marker-assisted selection; perception; social perception; forest genomics; biotechnology; tree breeding; forest stakeholders

\section{Introduction}

Following a decade of economic struggles for the forest industry, the Canadian government has been exploring alternative methods to traditional tree breeding in an effort to adapt to transforming markets and climate change. Forest genomic research is one area of innovation where the government has invested time and resources (over \$120 million since 2001) to help meet the ambitious goals of the Canadian forest sector [1].

Forest genomic research is a rapidly expanding field that aims to improve forest productivity and health. Serving as an additional tool to tree breeders, marker-assisted selection (MAS) is a type of biotechnology that uses molecular genetic markers as indirect selection criteria for desired traits [2,3]. Markers tend not to have any biological effect, but rather can be thought of as notable and constant points of reference within the genome [4]. In contrast to genetic engineering (GE), MAS does not alter 
the original DNA [5]; rather, it serves as a diagnostic tool to identify individuals carrying desired genes, so that individuals with the best potential can be selected [6].

MAS is considered a "revolutionary" approach to traditional tree breeding as it allows breeders to select individuals based on their genotypes, rather than being restricted to phenotypic characteristics [6]. Theoretically, the greatest strengths of molecular markers are its timeliness and efficiency for which individuals can be selected while maintaining the same level of breeding progress as conventional practices [6,7]. As many preferred traits are not observed until maturity, MAS eliminates this waiting period by allowing for the early selection of desired genotypes at the seedling stage [8]. In trees, this is a significant amount of time. For example, Picea glauca (white spruce) achieves maturity at approximately 30 years of age [9]. MAS provides several other benefits to breeders, in that it can select for traits that demonstrate low heritability, have recessive alleles, and are difficult, expensive, or time exhaustive to determine phenotypically $[3,6,7]$. MAS allows for gene pyramiding or combining multiple genes within the same breeding line, while having fewer unintentional losses and fewer selection cycles [6,7]. Whether a trait is controlled by a single or few genes (such as disease resistance), or is a complex quantitative trait that includes many genes (such as wood density), genetic markers provide a level of genomic information that is not achievable in conventional breeding practices. MAS can be used to rapidly review the DNA of thousands of individual trees so that the few with the best mix of preferred genes can be identified [10].

As with any tool, MAS is imperfect and breeders must also consider the limitations of using it in a forest setting. For instance, developing and applying the technology is expensive and some have argued that the genetic gains may not offset these costs [6,8]. Moreover, the markers developed for one population may not be transferable to another population [6]. This could compound the monetary costs associated with startup and labour. Furthermore, molecular markers are most commonly linked to a gene determining a trait of interest, rather than being located within the gene of interest [3]. Depending on the distance between the marker and the gene of interest, there will be a level of error from recombination [3]. The breeder will thus need to decide on an acceptable error rate for the breeding program (i.e., 5\%) leading to possible false positives [6].

British Columbia (BC) represents a cornerstone of the forest industry in Canada and has been one of the key provinces in exploring the potential of MAS in its forests. With a strong softwood lumber market in the United States (US), and expanding markets in China and Japan, BC remains the dominant source for softwood lumber exports in Canada. However, shifting markets and new low cost competitors have led BC to consider alternative methods to ensure lasting competitiveness. By providing breeders with an additional tool to select for wood quality traits, MAS could help breeders grow trees that demonstrate desired characteristics in a timelier fashion.

Yet for tree breeders to use a diagnostic tool like MAS to supplement traditional tree breeding, it must be cost effective [8]. Prices have dropped from over $\$ 5000$ per sequenced $\mathrm{Mb}$ in 2001 to just over $\$ 0.10$ per sequenced $\mathrm{Mb}$ in 2011 [11]. In a study that examined genomic selection in Eucalyptus, it was estimated that progeny tests performed on 20,000 individuals would cost $\$ 51$ USD per seedling [12]. In terms of optimizing net present value, a study examining the potential of genetically improved white spruce trees in Quebec found that the optimal economic rotation age can be reduced by up to nine years depending on the genetic improvement technique applied [13]. It is expected that genotyping costs will continue to come down and become more affordable [12], suggesting that in the future, economics will not be the key driver restricting its use in $\mathrm{BC}$ forests.

The other challenge of MAS is assessing its social acceptability. Currently, there is a poor understanding of the 'social license' BC breeders have in adopting this technology. For a tool that is being designed for forest applications, social acceptance will likely be the greatest hurdle. In $\mathrm{BC}$, there are several important groups whose opinions must be heard in discussions surrounding the forests. Government and industry are the most obvious, as the government is the legal owner of the land (95\%), and industry represents those forest companies, individuals, or other legal bodies, that acquire forest licences from the government for logging. Other relevant partners in forest-related discussions 
are environmental non-governmental organizations (ENGOs), and First Nations (First Nations in this context is used to describe Aboriginal peoples of Canada that are neither ethnically Inuit nor Métis).

The intent of this research study was to explore the social acceptability of MAS as an alternative to traditional tree breeding methods. Our aims were to determine how the implementation of MAS as a forest genomic tool is perceived in $\mathrm{BC}$, and determine if that perception is dependent on the context of implementation. To meet these objectives, a mixed-methods approach was taken to survey forest stakeholders and First Nations in BC.

\section{Materials and Methods}

\subsection{Research Design and Rationale}

This research study employed both qualitative and quantitative methods to address the research questions.

For the qualitative inquiry, semi-structured individual interviews were employed. Interview questions were open-ended in nature, and focused on both participant and organizational perception and attitude towards the use of MAS (the Interview Guide is available online in supplementary material). All interviews were audio recorded and subsequently transcribed verbatim for analysis.

For the quantitative inquiry, a questionnaire was developed. Firstly, the questionnaire collected socio-demographic information about the participant (age, gender, residence, education, etc.). Secondly, it served as a pre- and post-video knowledge comprehension test. For those participants unfamiliar with MAS, it was tested to see if their level of understanding improved following the video (described below). Furthermore, the pre- and post-test informed the interviewer which participants had a priori knowledge of the technology.

The remaining portion of the questionnaire required participants to rank their responses using a five-point Likert scale (from 1-strongly agree, to 5-strongly disagree). Here we explored perceived interest, support, and usefulness of MAS in different contexts. The statements developed for the Likert scale complemented the questions designed for the qualitative interview, however, were different enough to avoid overlap and repetition (the complete Likert scale questionnaire is available online in supplementary material). It was assumed that each population was normally distributed. Observations collected here were independent of each other and a Bartlett's test was used to ensure population variances were equal $(\alpha=0.05)$. Where significant differences were found between the ranked means, a Scheffé's Test was performed to determine where the differences occurred. Since purposive sampling was employed, observations were not randomly selected from each population; therefore, findings described from questionnaire data may not be generalizable to the entire population.

An educational package was prepared for the interviews. It was expected that prior knowledge of MAS would range among participants, so an informative video was used to ensure that all participants at least knew what MAS was and how it can be used in forestry. The educational package consisted of a video that was originally prepared and aired on Télé-Québec as part of the educational series, Le Code Chastenay (the complete video script is available online in supplementary material). The production company granted permission to use this video in this research study with verbatim English voice-overlays.

\subsection{Sampling of Social Groups}

Purposive sampling was employed in this study. It was imperative that participants, or the companies/organizations that they worked for, were either involved in silviculture practices in $\mathrm{BC}$, or were active participants in discussions that concern silviculture practices in BC. It was also necessary that these individuals were aware of Provincial practices, policies, and regulations concerning forestry (see Table S1 in Supplementary Material). We identified four main groups in the Province whose voices are typically involved in decisions concerning the forests: government, industry, 
First Nations, and ENGOs. For this reason, it was imperative that each group be represented in this study. Potential participants were invited by mailed-letter. Interviews were scheduled and performed with 25 respondents. This sample size was deemed satisfactory, as 15 to 20 interviews are typically required to achieve data saturation for themes in qualitative studies [14]. Ethical approval was sought and approved by the University of British Columbia's Behavioural Research Ethics Board (H13-00594).

\subsection{Data Analysis}

The qualitative data was analyzed using NVivo 10 (QSR International, Doncaster, Australia). Each interview was coded for affect (i.e., positive, neutral, or negative first impression of MAS) or theme. Themes were identified by the frequency of which all participants made reference to a certain idea. If a single participant repeated an idea, it was not duplicated in the tally of references towards that theme; therefore, one reference was given per participant per idea. Queries were conducted by social group (i.e., government, industry, First Nations, and ENGOs), and thematic trends were noted. Relative frequencies were calculated by social group and by sample.

The quantitative data from the questionnaires were analyzed and ANOVA was calculated using $\alpha=0.05$. Where the $F$ critical value was smaller than the $F$ stat value $\left(F_{\text {stat }}>F_{\text {critical }}\right)$, a Bartlett's test was performed to ensure variances were equal. Scheffé's Tests and confidence intervals were calculated to determine significant differences between social group responses, and a k-means cluster analysis was performed with 2, 3, and 4 clusters using Statistical Package for the Social Sciences (SPSS, Version 23.0, IBM Corp., Armonk, NY, USA).

\section{Results}

\subsection{Sample Population}

Of the 62 contact letters sent, we observed a response rate of $46.8 \%$. Of the 29 respondents, we were able to schedule and perform interviews with 25 individuals. Table 1 shows the distribution of participants by categorized group, gender, and residence. The sample was comprised of more males than females, and the majority of participants lived in rural communities. The median age among participants ranged between 51 and 60 years.

Table 1. Distribution of participants by categorized group, gender, and residence.

\begin{tabular}{cccccc}
\hline Participant Group & Male & Female & Rural & Urban & Total \\
\hline Industry & 5 & 1 & 5 & 1 & 6 \\
Government & 7 & 2 & 9 & 0 & 9 \\
First Nations & 3 & 3 & 5 & 1 & 6 \\
ENGOs & 3 & 1 & 0 & 4 & 4 \\
\hline
\end{tabular}

ENGOs, environmental non-government organizations.

Of the four categorized groups, government had the highest level of average education, with the majority having earned a Master's Degree (Figure 1).

\subsection{Comprehension Test}

Across all groups, the educational video improved participant understanding of MAS. Preceding the qualitative interviews, $56 \%$ of participants had no prior knowledge of MAS, and another $16 \%$ stated that they were only somewhat familiar with the technology (Figure 2). 


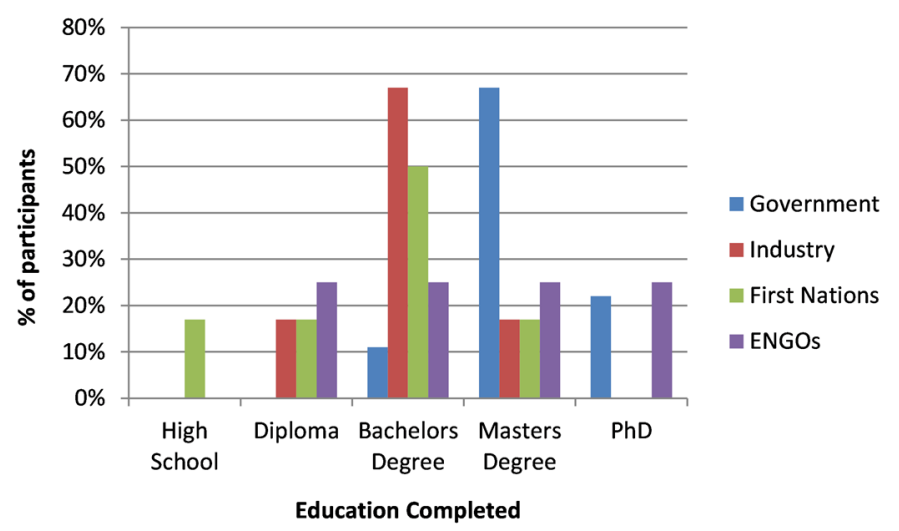

Figure 1. Distribution of completed education, represented as a proportion of categorized group.

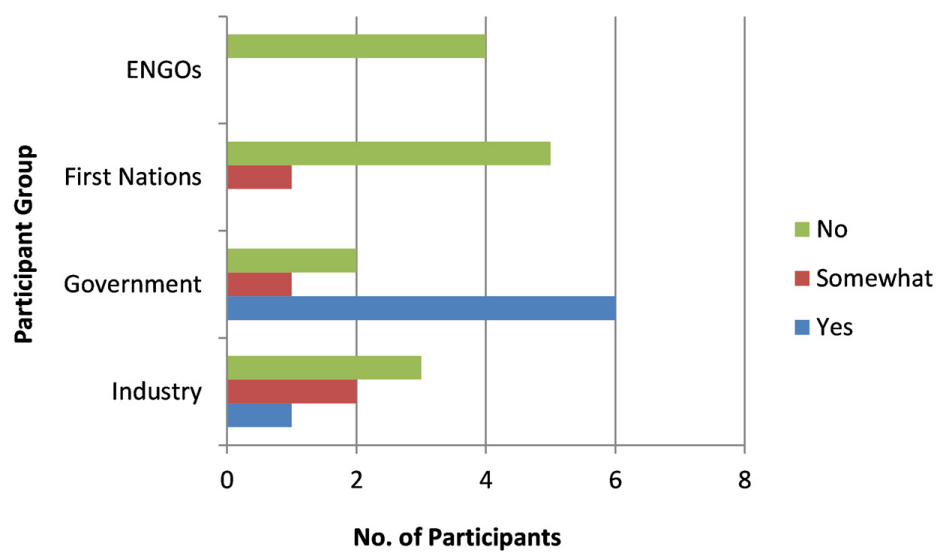

Figure 2. Participant familiarity with marker-assisted selection (MAS) a priori interviews.

All those that said that they were familiar with MAS answered the pre- and post-video question correctly ( $28 \%$ of total sample), and all those that indicated that they were somewhat familiar with MAS answered the post-video question correctly. Of the 14 participants that were not familiar with MAS, 11 answered the post-video question correctly. Figure 3 summarizes the distribution of correct answers, pre- and post-video. It should be noted that the pre- and post-video comprehension questions were exactly the same.

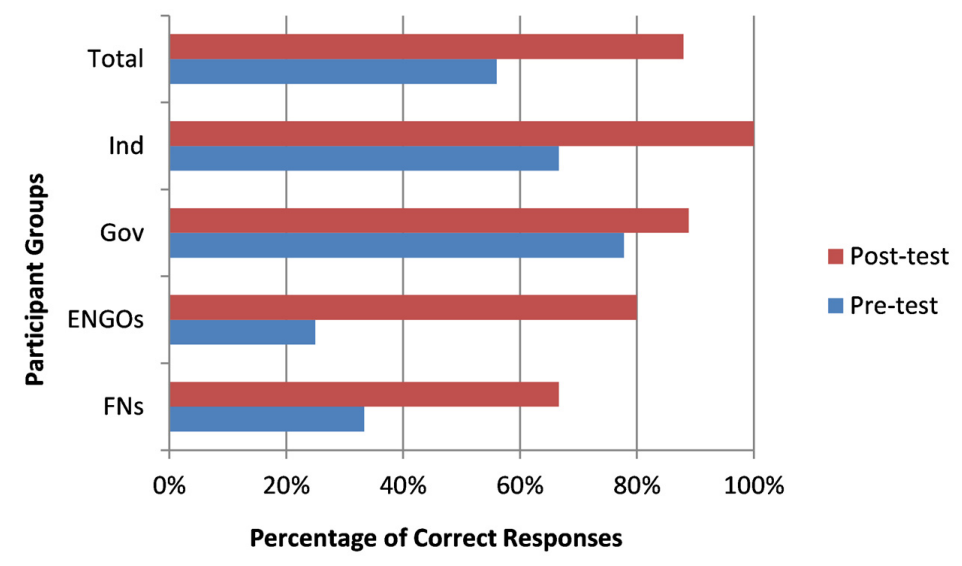

Figure 3. Distribution of correct answers to the pre- and post-video comprehension question, represented by proportion of categorized group. Ind, Industry; Gov, Government; FNs, First Nations. 


\subsection{Perceptions on the Implementation of Forest Genomic Tools in BC}

\subsubsection{Interview Data Findings}

Participants were asked to report their first impressions of MAS. As seen in Table 2, the majority of participants had a positive first impression (64\%), while only $8 \%$ of participants stated that their first impressions were negative. Industry demonstrated the highest level of initial impression, with all members reporting it to be positive. The only group to report a negative first impression was First Nations.

Table 2. Reported first impressions of MAS, represented as a proportion of members within a group and as a sample population total.

\begin{tabular}{cccc}
\hline & Positive & Neutral & Negative \\
\hline Industry & $100 \%$ & & \\
Government & $77.8 \%$ & $22.2 \%$ & \\
First Nations & $16.7 \%$ & $50.0 \%$ & $33.3 \%$ \\
ENGOs & $50.0 \%$ & $50.0 \%$ & \\
Total & $64.0 \%$ & $28.0 \%$ & $8.0 \%$ \\
\hline
\end{tabular}

Next, participants were asked to discuss their organization's anticipated attitude towards the use of general genomic tools in the forests of BC. The level of positive and neutral responses decreased (total positive responses reduced approximately by a third, and total neutral responses reduced by approximately two-thirds), while negative responses remained constant (Table 3). In this case, some participants additionally responded with greater frequency that they were either unsure of their organization's attitudes, that their organization held no attitude towards genomics, or that it depended on the context. Yet, when asked to discuss their organization's anticipated attitude towards the specific use of MAS in the forests of BC, participants responded with higher levels of positive, neutral, and negative attitudes when compared to general genomic tools (Table 4).

Table 3. Organization's attitude (as reported by participant) regarding genomic tools in British Columbia (BC) forests, represented as a proportion of each group and as sample population total.

\begin{tabular}{cccccc}
\hline & Positive & Neutral & Negative & None or Unsure & Depends on Context \\
\hline Industry & $50.0 \%$ & $16.7 \%$ & & $33.3 \%$ & \\
Government & $88.9 \%$ & $11.1 \%$ & & & \\
First Nations & & & $33.3 \%$ & $33.3 \%$ & $33.3 \%$ \\
ENGOs & & & & $50.0 \%$ & $50.0 \%$ \\
Total & $44.0 \%$ & $8.0 \%$ & $8.0 \%$ & $24.0 \%$ & $16.0 \%$ \\
\hline
\end{tabular}

Although unsurprising that participants would have some uncertainty when asked to discuss their organization's anticipated opinion on a particular topic, it was striking that participants were more willing to rate their organization's expected attitude regarding MAS with greater certainty than genomic tools in general. Indeed, industry and government responded with elevated levels of positive attitudes (depressing all neutral opinions and half of the unknown opinions). Similarly, ENGOs and First Nations displayed decreased uncertainty (categorized as unknown and context dependent opinions), increasing their neutral and negative attitudes. When considering the total sample population, it was revealed that organizational attitudes towards MAS received higher proportions of positive, neutral, and negative attitudes (20\%,33\%, and 50\% respectively), compared to general genomics.

An examination of the interview transcripts revealed that government and industry expected their organizations to be more open and receptive to the specific use of MAS because it specifically did not involve any manipulation of DNA (i.e., differs from GE). These participants identified that 
they recognized the difference between genetic modification and MAS. GE is a controversial topic in the media in the context of food, plants, and forestry, and both government and industry participants explicitly recognized that MAS is simply an identification tool.

ENGOs and First Nations had different motives to explain their responses. ENGOs were generally more concerned about the potential ecological implications of using MAS. They expressed concerns of whether its use could potentially harm a tree's ability to adapt to climate change and/or reduce overall genetic diversity. While other ENGO participants communicated that a tool of this nature is not something their organization would readily weigh-in on, as it is a very specific technique and thus they would probably not follow it very closely.

First Nations took a more social stance. Some participants were concerned about how their community and/or elders would respond to the tool. One noted that his community would not like it, and that some would not even entertain a discussion about it. Another anticipated that people would have mixed feelings. A third participant explained that historical relationships with government and industry have left a profound gap in communication with communities. Although these relationships have been improving, this participant felt that geneticists and researchers are still not adequately consulting and accommodating First Nations when proposals could impact Aboriginal rights and title, leading to a lack of knowledge or awareness by the communities. This participant felt that until this gap is narrowed, there would be a continued level of distrust towards the research community.

Table 4. Organization's attitude (as reported by participant) towards the use of MAS in BC forests, represented as a proportion of each group and as a sample population total.

\begin{tabular}{cccccc}
\hline & Positive & Neutral & Negative & None or Unsure & Depends on Context \\
\hline Industry & $83.3 \%$ & & & $16.7 \%$ & \\
Government & $100.0 \%$ & & & & \\
First Nations & & $33.3 \%$ & $50.0 \%$ & & $16.7 \%$ \\
ENGOs & & $25.0 \%$ & $25.0 \%$ & $25.0 \%$ & $25.0 \%$ \\
Total & $56.0 \%$ & $12.0 \%$ & $16.0 \%$ & $8.0 \%$ & $8.0 \%$ \\
\hline
\end{tabular}

\subsubsection{Questionnaire Data Findings}

Figure 4 summarizes the responses received from the questionnaire. When participants were asked whether they agreed that the advantages of MAS outweighed the disadvantages, industry and government agreed while ENGOs generally disagreed. Industry (a) responses were statistically different than First Nations (b,c) and ENGOs (c); and government $(a, b)$ responses were significantly different than ENGOs (c) (Figure 4a).

Figure $4 \mathrm{~b}$ reflects participant replies when asked if their attitude towards the use of MAS in the forests of BC is positive. Again, industry and government agreed with this statement while ENGOs disagreed. Calculations confirmed that industry (a) and government (a) responses differed significantly from First Nations (b) and ENGOs (b).

When asked to rank their support for the continued investigation and research in forest genomic tools, we found that the mean responses for each group lay on the agreeable side of neutral (Figure 4c). Nonetheless, we found a statistically significant difference between government $(a, b)$ mean responses and ENGOs (c); and between industry (a) mean responses and ENGOs (c) and First Nation (b,c).

Figure 4d displays participant responses when asked to rank their personal support towards the implementation of MAS in BC forests. Although the assumption that variances are equal between populations was violated, the results were indicative of differences between industry (a) and government (a) responses when compared to First Nations (b) and ENGO (b) responses.

In summary of the findings expressed in Figure $4 \mathrm{a}-\mathrm{d}$, we consistently found that industry and government held more agreeable positions than First Nations and ENGOs. In all cases, industry mean responses were highest in agreeance (most closely to strongly agree) whereas ENGO mean responses 
were always the lowest. Government mean responses were always most closely adjacent to industry, while First Nation mean responses were always most closely related to ENGOs.

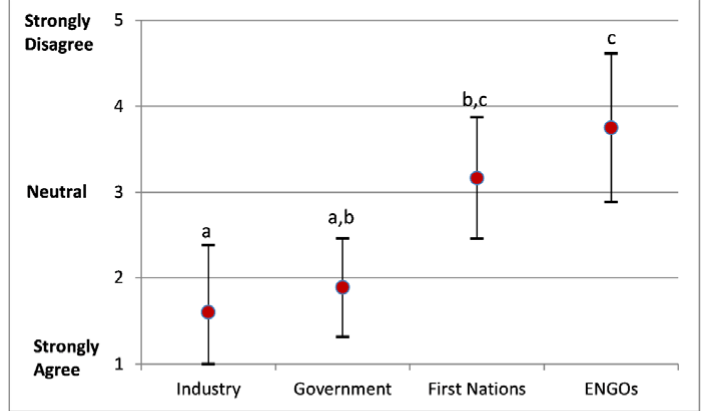

(a)

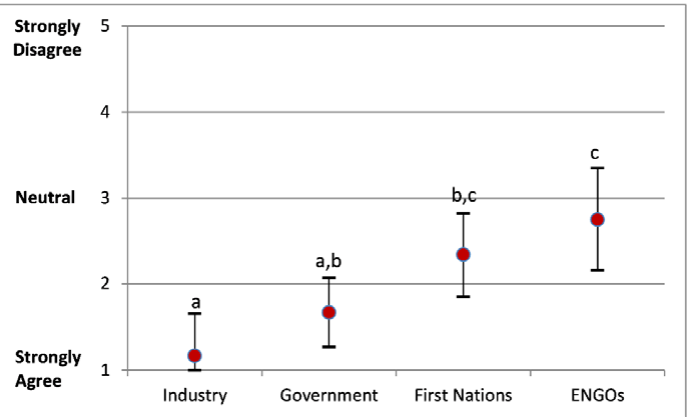

(c)

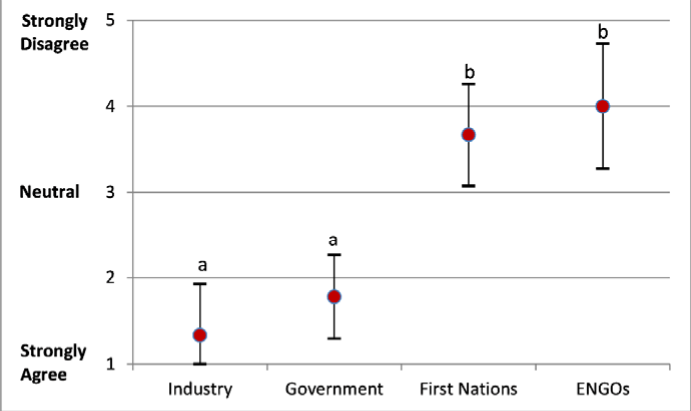

(b)

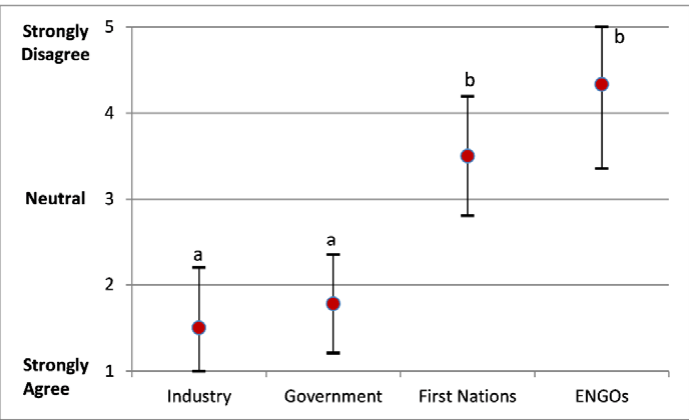

(d)

Figure 4. Mean levels of agreeance and 95\% confidence intervals by group to the following statements: (a) advantages of MAS outweigh the disadvantages; (b) attitude towards the use of MAS in the forests of $\mathrm{BC}$ is positive; (c) support the continued investigation and research in genomic tools; (d) support the implementation of MAS in BC forests. Significant differences are identified with lowercase letters, where different letters indicate a statistically significant difference between groups.

\subsection{Perception Dependency on the Context of Implementation}

\subsubsection{Interview Data Findings}

Table 5 summarizes the identified benefits of using MAS by participants. Across all groups, its usefulness in selecting for desired traits was most frequently identified.

Among industry and government participants, the benefits of MAS most often observed were its ability to select for traits to improve forest resiliency, industry-specific traits, and the additional benefits it would provide specifically to tree breeders. One industry participant articulated how MAS could aid in reaching free-to-grow status sooner. While one government participant voiced that MAS could reduce treatments (i.e., sprays).

First Nations uniquely expressed that MAS could be used to select trees that would have greater carbon sequestration capacity, and that it could be used to maintain First Nation values. For example, it could be used to improve breeding of medicinal plants and food plants that are culturally and economically important to First Nations.

ENGOs distinctively discussed its potential ability to reduce pressure from natural forests. Participants explained that agreements or moratoriums could be established so that certain areas could be allocated to forestry-related uses, and other areas could be conserved and protected.

Table 6 highlights the perceived concerns that were identified in the interviews. Of all the concerns that were identified, impacts to genetic diversity and increased susceptibility/reduced resiliency were the two most commonly identified issues by all groups ( $48 \%$ and $44 \%$, respectively). Other issues that 
were described with notable relative frequency across all groups were that MAS could have unknown impacts to ecosystems, that the tool is expensive to use with unknown additional training and facility costs, that public and First Nations perceptions may be negative, and that it is difficult to predict which traits will be desired by the industry 50 years from now.

Table 5. Identified benefits of MAS, represented as the relative proportions by group and of the total sample population, calculated using relative frequencies.

\begin{tabular}{|c|c|c|c|c|c|}
\hline Identified Benefits & Industry & Government & First Nations & ENGOs & Total \\
\hline \multicolumn{6}{|l|}{ Forest regeneration benefits } \\
\hline 1. Selection of traits & $83.3 \%$ & $88.9 \%$ & $100.0 \%$ & $100.0 \%$ & $92.0 \%$ \\
\hline \multicolumn{6}{|l|}{ Industry focused traits } \\
\hline General & $50.0 \%$ & $66.7 \%$ & $66.7 \%$ & $50.0 \%$ & $60.0 \%$ \\
\hline Wood quality/density & $16.7 \%$ & $55.6 \%$ & & $25.0 \%$ & $28.0 \%$ \\
\hline \multicolumn{6}{|l|}{ Improve forest resilience } \\
\hline Climate change adaptation & $66.7 \%$ & $33.3 \%$ & $50.0 \%$ & $25.0 \%$ & $44.0 \%$ \\
\hline Pests/diseases & $66.7 \%$ & $44.4 \%$ & & $25.0 \%$ & $36.0 \%$ \\
\hline \multicolumn{6}{|l|}{ Maintain/improve forest ecosystem } \\
\hline Faster growing trees & $16.7 \%$ & $22.2 \%$ & $33.3 \%$ & $25.0 \%$ & $24.0 \%$ \\
\hline Knowledge from genes & $33.3 \%$ & & $33.3 \%$ & & $16.0 \%$ \\
\hline \multicolumn{6}{|l|}{ Forest industry-specific benefits } \\
\hline 2. Usefulness for plantation planting & & & $33.3 \%$ & $50.0 \%$ & $16.0 \%$ \\
\hline 3. Cost effective & $16.7 \%$ & $11.1 \%$ & $16.7 \%$ & & $12.0 \%$ \\
\hline Reduce fill planting & $16.7 \%$ & $11.1 \%$ & $16.7 \%$ & & $12.0 \%$ \\
\hline Reduce brushing & & $11.1 \%$ & $16.7 \%$ & & $8.0 \%$ \\
\hline Reduce treatment & & $11.1 \%$ & & & $4.0 \%$ \\
\hline Achieve free-to-grow sooner & $16.7 \%$ & & & & $4.0 \%$ \\
\hline \multicolumn{6}{|l|}{ Tree breeder benefits } \\
\hline 4. Time saving & $100.0 \%$ & $100.0 \%$ & $50.0 \%$ & $25.0 \%$ & $76.0 \%$ \\
\hline 5. Additional tool to breeders & $66.7 \%$ & $66.7 \%$ & $16.7 \%$ & & $44.0 \%$ \\
\hline 6. Increase screening capacity & $16.7 \%$ & $77.8 \%$ & $16.7 \%$ & & $36.0 \%$ \\
\hline \multicolumn{6}{|l|}{ Other benefits } \\
\hline 7. Reduce pressure & & $11.1 \%$ & & $50.0 \%$ & $12.0 \%$ \\
\hline 8. First Nations values & & & $16.7 \%$ & & $4.0 \%$ \\
\hline 9. Carbon storage & & & $16.7 \%$ & & $4.0 \%$ \\
\hline
\end{tabular}

Table 6. Identified concerns of MAS, represented in relative proportions by groups and by the total sample population, calculated using relative frequencies.

\begin{tabular}{|c|c|c|c|c|c|}
\hline Identified Concerns & Industry & Government & First Nations & ENGOs & Total \\
\hline \multicolumn{6}{|l|}{ Unknown Impacts } \\
\hline 1. Impacts to genetic diversity & $50.0 \%$ & $22.2 \%$ & $50.0 \%$ & $100.0 \%$ & $48.0 \%$ \\
\hline 2. Increase susceptibility/reduce resiliency & $33.3 \%$ & $11.1 \%$ & $66.7 \%$ & $100.0 \%$ & $44.0 \%$ \\
\hline 3. Impacts to ecosystem & & & $83.3 \%$ & $100.0 \%$ & $36.0 \%$ \\
\hline 4. Impacts from breeding with wild populations & & & & $25.0 \%$ & $4.0 \%$ \\
\hline \multicolumn{6}{|l|}{ Issues with technology } \\
\hline 5. Expensive to use (technology, facility and/or training) & $16.7 \%$ & $55.6 \%$ & $33.3 \%$ & & $32.0 \%$ \\
\hline 6. Unsure which traits will be desired in future & $33.3 \%$ & $22.2 \%$ & $16.7 \%$ & $25.0 \%$ & $24.0 \%$ \\
\hline 7. Expensive to develop tool & & $44.4 \%$ & & & $16.0 \%$ \\
\hline 8. Exploitation of industry desired traits & & & $33.3 \%$ & $50.0 \%$ & $16.0 \%$ \\
\hline 9. Genes do not determine all phenotypes & $16.7 \%$ & $22.2 \%$ & $16.7 \%$ & & $16.0 \%$ \\
\hline 10. Traits of interest involve many genes & & $33.3 \%$ & & & $8.0 \%$ \\
\hline \multicolumn{6}{|l|}{ Implementation issues } \\
\hline 11. Perception by public and/or First Nations & $50.0 \%$ & $33.3 \%$ & $16.7 \%$ & & $28.0 \%$ \\
\hline 12. Need for policy defining usage & $16.7 \%$ & $11.1 \%$ & & $25.0 \%$ & $12.0 \%$ \\
\hline 13. Does not replace field tests & $33.3 \%$ & $11.1 \%$ & & & $12.0 \%$ \\
\hline
\end{tabular}

Uniquely to government participants, it was discussed that MAS and marker technologies in general have been very expensive to develop. Also, several traits of interest involve many genes, 
which would be inherently more difficult to select for. Government and industry participants were the only two groups that expressed that markers technologies would not replace field tests, and that progeny testing and the identification of superior trees would still need to occur.

Although participants were not specifically asked in the qualitative interviews to report which traits MAS could be useful in selecting, participants routinely identified said traits. Table 7 summarizes that $44 \%$ of all participants articulated that MAS could be used in the selection of volume/growth/productivity traits, while 36\% expressed its potential use in resistance/resilience against pests and diseases, and general forest management traits. Government was the only group that identified wood density as a selectable trait, while government and industry were the only two groups to identify its use in comparing relatedness and genetic gain among individuals and species.

Table 7. Desirable traits where MAS could facilitate selection, and represented as a proportion of each group and by the total sample population, calculated by using relative frequencies.

\begin{tabular}{|c|c|c|c|c|c|}
\hline Selection of traits & Industry & Government & First Nations & ENGOs & Total \\
\hline 1. Volume/growth/productivity & $50.0 \%$ & $33.3 \%$ & $50.0 \%$ & $50.0 \%$ & $44.0 \%$ \\
\hline 2. Resistance/resilience & $50.0 \%$ & $33.3 \%$ & $16.7 \%$ & $50.0 \%$ & $36.0 \%$ \\
\hline 3. General forest management & $50.0 \%$ & $11.1 \%$ & $66.7 \%$ & $25.0 \%$ & $36.0 \%$ \\
\hline 4. Wood quality & $50.0 \%$ & $33.3 \%$ & & $25.0 \%$ & $28.0 \%$ \\
\hline 5. Fibre/structural strength/straightness & & $33.3 \%$ & $16.7 \%$ & $25.0 \%$ & $20.0 \%$ \\
\hline 6. Climate change adaptation & $16.7 \%$ & $33.3 \%$ & $16.7 \%$ & & $20.0 \%$ \\
\hline 7. For industry-specific traits & $33.3 \%$ & & $16.7 \%$ & $50.0 \%$ & $20.0 \%$ \\
\hline 8. Wood density & & $33.3 \%$ & & & $12.0 \%$ \\
\hline 9. Compare relatedness/genetic gain observed & $16.7 \%$ & $22.2 \%$ & & & $12.0 \%$ \\
\hline
\end{tabular}

\subsubsection{Questionnaire Data Findings}

Figure 5 demonstrates the mean responses by group when participants were asked to rank their perceived usefulness of MAS in various contexts when used in a forest management framework in BC. Respondents displayed similar views in three of the scenarios: increasing timber production, increasing timber quality, and adding value to wood products. In all three cases, mean participant responses within groups fell between 'strongly agree' to 'neutral'. In each of these scenarios, industry showed the highest level of agreeably (most closely to 'strongly agree'), closely followed by government. First Nations were the least agreeable in these three cases (most closely to 'neutral'). There was no statistically significant difference in participant grouped responses for 'increasing conservation areas' or for 'rehabilitating sites and/or degraded sites'.

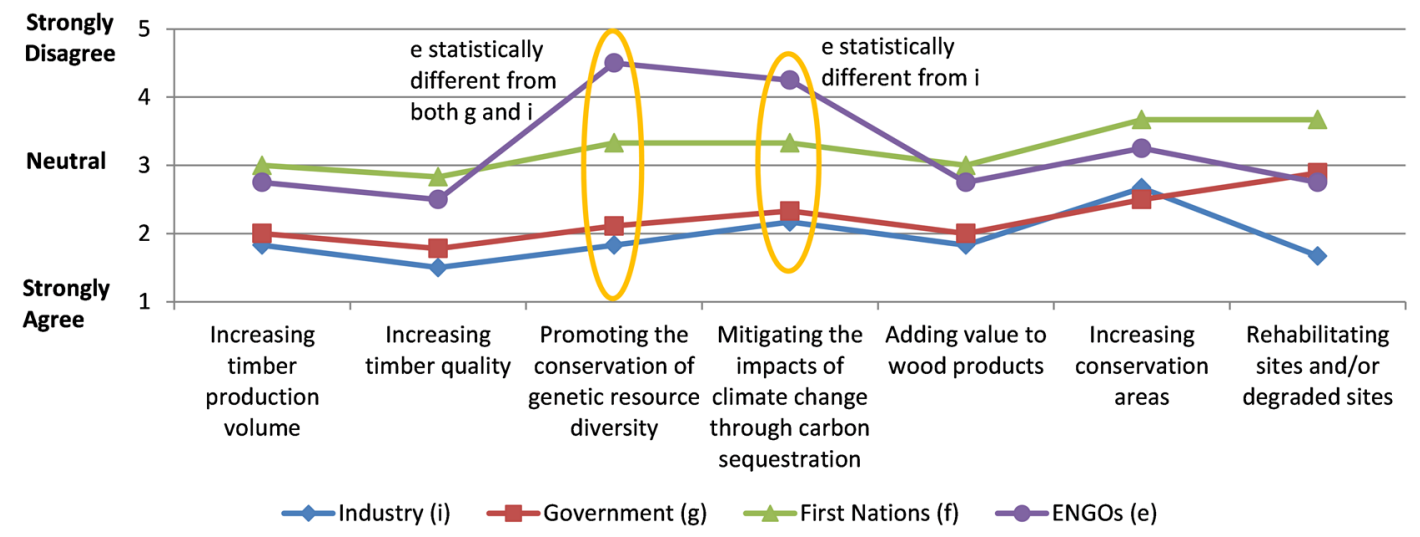

Figure 5. Mean response by group for usefulness of MAS as a tool if used in a forest management framework in BC. Circles denote significant differences revealed through ANOVA and Scheffé's Tests $(\alpha=0.05)$. Notes indicated where the statistically significant differences exist with $i, g, f$, and e denoting mean scores for Industry, Government, First Nations, and ENGOs, respectively. 
ENGOs demonstrated a significant difference in ranked mean response to government and industry for 'promoting the conservation of genetic resource diversity'. There was also a significant difference in ranked mean for 'mitigating the impacts of climate change through carbon sequestration'. Interestingly, the Scheffé's Test and confidence intervals did not reveal where the significant difference lay. As the null hypothesis was rejected, at least one contrast must exist, thus the significant difference lies between the two most extreme means [15]. In this case, industry and ENGO group means were significantly different.

\subsection{K-Means Cluster Analysis}

Although trials were completed using 2, 3, and 4 clusters, no apparent trends or patterns appeared using the socio-demographic information collected. This is likely a result of the small sample size. Nonetheless, it can be stated that attitudes did not seem to have a discriminating power, or that patterns of responses seem to be similar across all groups.

\section{Discussion}

\subsection{Attitudes and Perceptions of MAS in BC Forests}

Generally speaking, industry and government demonstrated more favourable attitudes towards genomic tools and MAS. Both the qualitative and quantitative data endorse the notion that both groups are strongly supportive about the continued investigation and the future use of MAS in BC forests. Between the two groups, government was more favourable in their attitudes regarding genomics and MAS. This was expected as government has been investing and collaborating on genomic projects (such as AdapTree and SMarTForests) with the University of British Columbia. Moreover, the Tree Improvement Branch within the Ministry of Forests, Lands, and Natural Resource Operations has a number of researchers currently working on molecular marker projects.

Surprisingly, industry displayed higher levels of average agreeance and support of MAS compared to government in the quantitative questionnaire; however, there was no statistically significant difference in responses between these two groups. It is possible that government was more conservative in their responses on the questionnaire, because as a group they are more informed about the technology. In the interviews, government participants stated a number of times that although they are eager to use this tool, they require more conclusive evidence of its efficiency and effectiveness before they will fully endorse it. Government participants may have been more cognisant to make statements like this because they are aware of the slow progress that has been made in this field, which is consistent with the literature, stating frequently that MAS remains an unfulfilled promise that lags behind expectations $[4,7,16,17]$.

First Nations and ENGOs demonstrated less favourable attitudes towards MAS and genomic tools than industry and government. First Nations held stronger negative attitudes than ENGOs in the qualitative interviews, while ENGOs tended to disagree more strongly to the statements in the quantitative questionnaire. Although this trend emerged in the quantitative data, there was no statistically significant difference in responses between these two groups. Moreover, in spite of each groups' views, both generally supported the continued research and investigation in genomics.

ENGOs generally held an indifferent attitude towards MAS, stating that they would only be concerned if it reduced genetic diversity. This infers that support could be gained by ENGOs if they were further informed about the technical details of MAS, and how its use is not anticipated to reduce genetic diversity any more than traditional tree breeding techniques [3]. In fact, markers can support trials to expand the genetic base and maintain diversity at each step [3].

First Nations support could also be improved. The interviews revealed that First Nation communities are often excluded from technological and forest management discussions, particularly by geneticists and researchers. Participants stressed that communities would need field trials to gain support for this tool, but that relationship building with communities would be equally necessary. 
Currently there remains a lack of trust with the research community, which stems from a legacy of disengagement, lack of consultation, and minimal communication by government and industry. Improving these relationships could enable more open discussions around new tools, technologies, and methods to be used in forest management.

The results gathered from the qualitative interviews indicated that all participant groups had more defined attitudes towards MAS than genomic tools in general. Analysis of the interviews suggests that the specificity of MAS permitted participants to consider its potential implications more acutely. This may have warranted a stronger opinion about their organizations' expected perceptions towards MAS, leaving more cautious responses for the more blanket and abstract ideas like genomic tools in general.

\subsection{Perception in the Context of Implementation}

\subsubsection{Perceived Benefits of MAS}

Qualitative analysis identified several perceived benefits of MAS. Among all groups, its ability to select for desired traits was the most frequently reported. In fact, 23 of the 25 participants $(92 \%)$ specified this benefit at least once in their interview. Forest regeneration benefits and tree breeder benefits were two categories most commonly identified among participants. Within the forest regeneration benefits category, industry focused traits and improved forest resiliency were discussed often. In fact, $60 \%$ of participants articulated its potential ability to select for industry focused traits, $44 \%$ stated its potential ability to help in climate change adaptation, and $36 \%$ noted its potential use against pests and diseases. For climate change adaptation and pest/disease resistance, industry participants discussed these two benefits with the highest frequency.

Another benefit commonly identified by all groups was MAS's time saving ability in the tree breeding process (identified by 19 of the 25 participants $(76 \%)$ ). Other notable benefits to the tree breeding process are that MAS would serve as an additional tool (44\%), and increase the screening capacity (36\%), for tree breeders. Government and industry emphasized that MAS would not replace field trials and provenance testing, but its ability to speed up the screening process, both in the selection stage and in future mitigation efforts, would be useful. One participant stated that he is producing trees today that may be planted 15 years from now, and then subsequently harvested 50 years after that. As such, having screening tools like MAS would help breeders combat new pests or diseases that are not an issue today, ensuring seedlings planted are resilient.

An interesting benefit discussed by a few participants was that MAS could relieve harvesting pressure from other stands. Here it was described that if this tool could be used to increase timber production in a given area (i.e., produce a greater amount of cubic metres of wood), and if met with a well-designed policy or moratorium, other areas could be conserved from harvest. This is because a company would theoretically be able to reach their maximum harvestable volume within a smaller area; hence other areas could be protected from harvest. Moreover, ENGOs argued further that industry desires a certain level of wood quality, so if this tool could achieve that level elsewhere, this may relieve pressure off of old-growth stands.

Approximately a quarter of the participants identified that MAS could be used to produce faster growing trees, which would improve the forest ecosystem. Regenerating a stand in a more timely fashion could be beneficial for wildlife habitat by reducing wildlife corridors.

\subsubsection{Perceived Concerns for MAS}

The qualitative interviews revealed concerns that were categorized as: unknown impacts, issues with the technology, and implementation concerns. Of all identified concerns, unknown impacts were the most frequent. Careful inspection of this category reveals that it could have been alternatively classified as environmental concerns. The three most frequently reported concerns within this set were: impacts to genetic diversity, increased susceptibility (or reduced resiliency), and impacts to ecosystems. 
Each of these is generally related to decreased diversity. However, according to Brumlop and Finckh, MAS can actually be used to broaden the genetic base of species, ensuring that diversity is maintained or improved [3]. Several published articles discuss how MAS has the potential to increase genetic variation by more easily incorporating wild seeds into breeding programs, compared to traditional breeding $[5,7,18]$.

Interview queries showed that concerns subsequently categorized as 'impacts to the ecosystem' were largely discussed in the context of reduced species diversity across the landscape. This specifically included reduced ecological diversity and ecosystem degradation resulting from intensive forest management. Some participants expressed that unfavourable characteristics may play an unknown evolutionary role in the forest, and that by reducing their natural presence, we may be negatively impacting the long-term health of the whole ecosystem.

ENGOs and First Nations were further concerned that MAS would facilitate the application of monocultures or plantations following harvest. However, this concern cannot be argued exclusively to MAS and genomic tools, but rather to any harvested area that is subjected to intentional reforestation. Concerns of this nature can be (and have been) addressed by regulations set by the provincial government. Forest Planning and Practices Regulations under the Forest and Range Practices Act (FRPA) outline stocking standards under Section 26. This regulation requires that stands be restocked "with ecologically suitable species that address immediate and long-term forest health issues on the area" [19]. Former Chief Forester Jim Snetsinger elaborated in the 2009 memorandum on Guidance on Tree Species Composition at the Stand and Landscape Level that developed stocking standards should be mindful of existing species diversity, species vulnerability due to climate change, potential risks of insects and diseases, and maintenance of natural diversity at the forest level [20]. Nonetheless, future implementation regulations designed to address the scope and usage of MAS should include species diversity requirements to acknowledge these concerns.

Perhaps unsurprisingly, ENGOs and First Nations participants identified environmental concerns with notable frequency. Environmental organizations are typically in the business of identifying and voicing potential negative impacts to ecosystems, individual species, and/or the environment, and First Nations cultural values and traditional practices are strongly connected to the forest. First Nation communities in $\mathrm{BC}$ are continually fighting land-use plans with government and industry in an effort to ensure a healthy forest ecosystem is maintained for social, environmental, and economic benefits.

Government participants expressed the strongest economic concerns. Although First Nations and industry recognized the expense in using this tool, no other group discussed the expense of developing such a tool. This monetary cost involved in using MAS was described in terms of the price to acquire and apply this technology, to undergo training on how to perform and interpret trials, and to invest in a facility to perform these tests. Government has already invested a substantial amount of money and resources into the research and development of MAS. It is thus not surprising that government participants spoke of their eagerness to see if the final deliverables will meet the proposed expectations and if the advantages come into fruition. This concern has likewise been addressed in the literature, stating that MAS will not be applied unless genetic gains can offset the cost of using the technology $[8,13]$. Eucalyptus simulation studies have already shown that the breeding cycle could be halved when early-selection methods are employed [12]. Additionally, the economic rotation age in genetically improved white spruce can be reduced by up to nine years [13]. Porth et al. recognized that the cost of producing seedlings is higher when genotyping is employed, however, this will be offset by increased volume, reduced timeframe, and the production of higher value products [1]. Nonetheless, to date little of the genomics budget has been spent towards economic analysis [1]. This concern should be addressed in future forest genomic research in Canada.

Government, industry, and First Nations participants also emphasized their concerns on public and First Nations perceptions towards MAS. Perception concerns were strictly focused on mistaking MAS for GE. This concern is supported by various studies done over the last 15 years that have assessed public perception towards GE and genetically modified organisms (GMOs), and the lack of 
public distinction from genomics. In studies done in the US and the European Union (EU), it was found that the public was generally uninformed about GE and genomic tools, and their current applications [21-25]. It was frequently reported that negative perceptions towards biotechnology are not based on objective knowledge but rather shaped by protest groups and media, or from distrust with big business companies in the US (namely Monsanto), and regulatory agencies in the EU [24-26]. Despite these views, the limited knowledge held by the public regarding biotechnology means that a flow of new and factual information can erode previous opinions over time [25]. Indeed, in a study by Heuvel et al. respondents that initially associated genomics more closely to GE than conventional breeding changed their views following explanations of each type of biotechnology, ultimately ranking genomics more closely to conventional breeding and deeming it incomparable with GE [22]. These two studies suggest that public awareness on biotechnology (and forest genomic tools more specifically) could and should be improved to mitigate this concern.

Another challenge identified by all participant groups is predicting what characteristics will be desired in trees 30,50, or 80 years from now. Several participants mentioned that it is difficult to predict how future pests, diseases, and climates will impact forests. One argued that MAS does not provide any reassurance that a population adapted to today's climate will be well adapted 60 years from now. Government participants also addressed the uncertainty of future markets and the difficulty in planning for the forest sector's future needs.

Although predicting and selecting for the 'right' traits is difficult (if not impossible), it is not a limitation of MAS. Rather it is a limitation of breeding strategies in general—especially in trees, which inherently develop and evolve over long time periods.

Lastly, some participants voiced the need for a well-defined policy to accompany the introduction of this tool to ensure responsible usage. Government, ENGO, and industry participants all recommended that percentage limitations should be set for the proportion of a stand that employs this type of seed selection. Currently, there are standards set by the Chief Forester for seed use in the province. These standards regulate where orchard seeds and wild seeds can be planted and how diverse the parents need to be. There are no existing policies or regulations that specifically address the use of genetic markers within public forests. Hence, although MAS is not prohibited from being used within the province, there are also no policies that guide or define its use. This differs from other types of biotechnology, such as genetic modification. Under provincial policy (Section 5.1.8e of the Chief Forester's Standards for Seed Use), the commercial use of genetically modified trees on public land is prohibited [27]. Since MAS is a diagnostic tool that is meant to assist tree breeders in the selection process, and does not involve any modification at the genetic level of an individual, its use is currently not restricted by provincial policy or regulation. Updating policies and/or regulations to define how MAS should be applied would promote its responsible usage.

\subsubsection{Perceived Usefulness of MAS}

All participant groups reportedly agreed that MAS could be useful in the context of increasing timber production volume, increasing timber quality, and adding value to wood products. It is not surprising that positive responses were received for these uses as the interviews revealed that $60 \%$ of all participants identified that MAS could be beneficial in the selection of industry-focused traits. Similarly, all participant groups shared a neutral stance towards the potential role of MAS in the context of increasing conservation areas and rehabilitating sites and/or degraded sites. These findings are consistent with the identified benefits, as less than a quarter of participants discussed its use in selecting traits that would improve the forest ecosystem, and only $12 \%$ of all participants made reference to its use in relieving pressure off other stands.

ENGOs held a significantly different position than government and industry in the context of promoting the conservation of genetic resource diversity. While ENGOs disagreed with this statement, government and industry agreed that MAS could be useful in this context. Again, this is likely because 
ENGOs are unfamiliar with the technical details of tree breeding and are unaware that MAS is not expected to reduce the genetic diversity any further than traditional breeding practices [3].

Lastly, industry and ENGOs demonstrated significantly different opinions regarding the usefulness of MAS in mitigating the impacts of climate change through carbon sequestration. While industry agreed with this statement, ENGOs disagreed. As with the previous scenarios, these results are consistent with the analysis of reported benefits. In fact, $66.7 \%$ of industry participants had identified that MAS could be used in climate change adaptation, compared to only $25 \%$ of ENGO participants.

\subsection{Connections to the Literature}

The conclusions made in the Pardo et al. study can be translated to the findings in this study [25]. As a sector that utilizes a wide range of progressive technologies, it may be assumed that government and industry generally have a favourable attitude towards technology. This technological optimism may further influence their more specific attitudes towards the promise of biotechnology. If these assumptions hold true, according to the proposed model in Pardo et al. then these two cognitive structures could be influencing their more specific positive attitudes toward biotechnology applications (such as MAS) [25]. Furthermore, government and industry participants entered this research study with the highest levels of prior knowledge on MAS (77\% and 50\%, respectively), while First Nations and ENGOs were mostly unaware of MAS (83.3\% and 100\%, respectively). According to Pardo et al., being part of the informed public can influence an individual's attitude towards specific biotechnological applications (such as MAS) [25].

Unfortunately, the Pardo et al. model does not inform us about which variables significantly influence a person's reservations towards biotechnology [25]. They concluded that traditional demographic and educational indicators were not useful in explaining perceived concerns [25]. However, we would argue from the findings in this study that an individual's level of scientific knowledge might play some role in shaping their attitude. One does not necessarily need to be familiar with specific biotechnologies and their applications, as even a more general scientific understanding of biology and genetics may shape individual attitudes. This idea is supported by an American study that concluded it was unsurprising that respondents were uncertain about genetically modified foods when they had little informed knowledge or basic factual awareness about transgenic technology [21].

Several studies and reports have discussed the negative public perception towards biotechnology, and how this perception has not been formed on objective knowledge [22-24]. In fact, the media has arguably played a large role in influencing people's opinions, often presenting highly credible sources against non-scientific yet charismatic opponents [24]. News reports often counter arguments supported by scientific data with proponents that believe something is safer, healthier, or 'better', but by not identifying to the audience that the belief is unsupported by factual evidence, viewers may assume that both arguments are equally credible and legitimate [24].

\subsection{Successful Implementation}

It is our opinion that successful implementation of MAS in BC forests will be preceded with a number of well-considered actions. We argue that it would be invaluable for advocates of forest genomic tools to develop an educational package to improve forest stakeholder and First Nations knowledge on forest biotechnologies. This information needs to be easily accessible by all parties. It is imperative that it is structured in layman's terms and assumes that the viewer has minimal a priori scientific background. Furthermore, this educational tool must not come across as a marketing ploy; it must be unbiasedly informing, portraying the strengths, weaknesses, and limitations of using molecular markers in a forest context. The educational tool should also present the potential benefits and concerns of MAS from a social, environmental, and economic context. This tool should be specific to the forests of $\mathrm{BC}$, and include the opinions of relevant forest representatives. According to other public perception surveys on biotechnology, scientific academics, consumer organizations, 
and environmental organizations are considered trusted sources of information by the public [23,24]. We believe that a tool developed in collaboration with government, academia, First Nations, ENGOs, and industry would provide a level of assurance and confidence to forest stakeholders and First Nations. This may include the Ministry of Forests, Lands and Natural Resource Operations, the University of British Columbia, the BC First Nations Forestry Council, Greenpeace BC, ForestEthics, Canfor, West Fraser Timber, and/or Tolko Industries.

To address the concerns that were raised around exploitation, reduced genetic diversity, and impacts to the ecosystem, we suggest developing a well-designed and well-defined policy framework. This could set limitations and define the usage of MAS in reforestation and forest management regimes, as well as regulate monocultures by setting standards that require multi-species compositions. Furthermore, forest certification schemes may need to be modified to set standards for using MAS in a management unit. This due diligence prior to implementation will assure all parties that cautious and thoughtful consideration was employed. This is particularly necessary as humans prescribe an emotive value to forests and trees [26]. Trees are significant to human culture and values, and have played a role in human history, mythology, and identity [26]. Indeed, they are the only plant or crop in which a vast portion of the population ascribe moral value [28].

MAS is a promising tool that could help improve forest productivity and forest health, but to do so, selection of markers must be chosen on a broader basis than economic value (such as wood quality and fibre characteristics). Resilience against pests and diseases, and climate change adaptability are also important in a sustainable forest management regime. MAS may help the provincial forest sector deliver an unmatchable timber product and increase production abilities, but it should also be used to support healthy forests.

Lastly, for MAS to be readily adopted and used in BC, it needs to be economically viable and requires social support. Genomic research is constantly evolving, and marker technologies in Canada are approaching a reality. Economic investments over the last dozen years have supported research and development, reducing the gap between economic costs and genetic gains. This study has shown that government and industry are supportive of the future implementation of MAS in BC forests, and with increased evidence that MAS will not reduce genetic diversity, ENGOs will likely take a neutral stance and remain at arm's length. Thus, of the forest-related groups surveyed in this study, gaining First Nations support will be pivotal. Field trials, consultation, and community engagement will likely be important actions in attaining this support.

\subsection{Limitations}

There were several limitations in this study. Firstly, the sample size was quite small. Since individual interviews were preferred for this study over focus groups, compounded by tight deadlines for data collection and a conservative budget, it was not possible to expand this study to include a larger sample size. Although the number of interviews exceeded the recommended sample size necessary to reach thematic saturation in qualitative research methods (15-20 participants) [14], it was restrictive in the quantitative data analysis.

A second limitation was the use of selective sampling. Since it was deemed important that participants were familiar with silvicultural practices, provincial standards, and forest policies and regulations, a purposive sample was employed. Although this is an acceptable method of sampling in qualitative research, it lacks an ability to be widely generalizable [29]. Furthermore, the public's opinion was excluded due to budgetary and time constraints. The results from several other research studies indicated that the public has very low knowledge on basic biology and agriculture [21,23], and it has been argued that meaningful results from discussions on biotechnology with the public cannot be expected [24,25]. As purposive sampling was used to restrict participation to individuals with a certain range of knowledge, the public's opinions were outside the scope of this study. 
The use of the educational video was another limitation. This video was not designed specifically for this research project, but was rather borrowed from a television broadcast station in Quebec. The original program was designed for a Quebecois audience and aired on a scientific television series in January 2008. Firstly, this meant that the information was a little outdated and not relevant to BC as the images, locations, researchers, and language was Quebec-centric. Secondly, since we did not have rights to alter the video aside from applying English-overlays, we could not alter the dialogue to include a more holistic representation of MAS. Since the video did not objectively present all the pros and cons of MAS, it is possible that participant attitudes may be biased towards or against MAS as a result of being influenced by the educational video.

\section{Conclusions}

This study surveyed three forest stakeholder groups and First Nations in BC with an aim of assessing how the implementation of MAS as a forest genomic tool is perceived in $\mathrm{BC}$, and determining if this perception is dependent on the context of implementation.

Through research interviews, government and industry were found to have positive perceptions towards the implementation of MAS in BC. Displaying support for its use and continued research, both groups identified its benefits in forest regeneration. ENGOs and First Nations demonstrated less favourable attitudes towards MAS, generally ranging between neutral and negative positions. Although both groups recognized the usefulness of MAS as a tool to support the forest industry, both showed concerns that it could have unknown environmental impacts, such as increased susceptibility, impacts to genetic diversity, and impacts to the ecosystem (including reduced biodiversity, ecosystem degradation, and monocultures). Among all groups, participants agreed that MAS allowed for the selection of preferred traits (notably for industry desired traits, climate change adaptation, and pest/disease resiliency), and that it would be time saving to tree breeders.

Drawing from the results of this study and its connections to the literature, an appropriate setting must be established before MAS can be successfully implemented in BC. This would include increased forest stakeholder and First Nation awareness and knowledge of biotechnology and its applications, a well-defined policy that addresses the limitations of its usage, and strengthening engagement and consultation with First Nations. If this road is adequately paved, a promising future for genomic tools in the forests of BC may exist.

Supplementary Materials: The following are available online at www.mdpi.com/1999-4907/7/11/286/s1, Table S1: Participant Job Titles.

Acknowledgments: Funds for this research project were received from J. Bohlmann and J. MacKay through Genome Canada, Genome Québec, Genome BC, and Genome Alberta for the SMarTForests Project (www.smartforests.ca). We also want to thank other contributors via smaller grants and awards, including the Mary and David Macaree Fellowship, the Three Minute Thesis Award from the Faculty of Forestry at the University of British Columbia (UBC), and the Graduate Student Travel Awards from the Faculty of Graduate and Postdoctoral Studies and the Faculty of Forestry (UBC). Genome Québec provided the funds to cover the costs to publish this article in open access.

Author Contributions: C.N., N.G., and G.B. conceived and designed the experiments; C.N. performed the experiments; C.N. analyzed the data; N.G. and G.B. contributed materials/analysis tools; C.N. wrote the paper; N.G. and G.B. reviewed the paper.

Conflicts of Interest: The authors declare no conflict of interest. The founding sponsors had no role in the design of the study; in the collection, analyses, or interpretation of data; in the writing of the manuscript, and in the decision to publish the results.

\section{References}

1. Porth, I.; Boyland, M.; Ahmed, S.; El-Kassaby, Y.A.; Bull, G. Forest Genomics Research and Development in Canada: Priorities for Developing an Economic Framework. For. Chron. 2015, 91, 60-73. [CrossRef]

2. Ashraf, M.; Akram, N.A.; Foolad, M.R. Marker-Assisted Selection in Plant Breeding for Salinity Tolerance. In Plant Salt Tolerance: Methods and Protocols; Shabala, S., Cuin, T.A., Eds.; Humana Press: Totowa, NJ, USA, 2012; Volume 913, pp. 305-333. 
3. Brumlop, S.; Finckh, M.R. Applications and Potentials of Marker Assisted Selection (MAS) in Plant Breeding; Bundesarnt fur Naturschutz (BfN), Federal Agency for Nature Conservation: Bonn, Germany, 2011.

4. Guimaraes, E.P.; Ruane, J.; Scherf, B.D.; Sonnino, A.; Dargie, J.D. Marker-Assisted Selection: Current Status and Future Perspectives in Crops, Livestock, Forestry and Fish; Food and Agriculture Organization of the United Nations: Rome, Italy, 2007.

5. Vogel, B.; van Aken, J. Smart Breeding-Marker-Assisted Selection: A Non-Invasive Biotechnology Alternative to Genetic Engineering of Plant Varieties; Greenpeace: Amsterdam, The Netherlands, 2009.

6. Boopathi, N.M. Marker-Assisted Selection. In Genetic Mapping and Marker Assisted Selection: Basics, Practice and Benefits; Springer: Tamil Nadu, India, 2013; pp. 173-186.

7. Xu, Y.; Crouch, J.H. Marker-Assisted Selection in Plant Breeding: From Publications to Practice. Crop Sci. 2008, 48, 391-407. [CrossRef]

8. Yanchuk, A.D. The Role and Implications of Biotechnology in Forestry. For. Genet. Resour. 2002, 30, 18-22.

9. Forest Practices Branch. Tree Species Compendium: White Spruce. Available online: www.for.gov.bc.ca/hfp. silviculture/compendium.whitespruce.htm (accessed on 23 April 2014).

10. Sedjo, R.A. Biotechnology for Planted Forests: An Assessment of Biological, Economic and Environmental Possibilities and Limitations. In The Economics of Managing Biotechnologies; Swanson, T., Ed.; Springer: Dordrecht, The Netherlands, 2002; pp. 71-95.

11. Poland, J.A.; Rife, T.W. Genotyping-by-Sequencing for Plant Breeding and Genetics. Plant Genome J. 2012, 5 , 92-102. [CrossRef]

12. Resende, M.D.V.; Resende, M.F.R.; Sansaloni, C.P.; Petroli, C.D.; Missiaggia, A.A.; Aguiar, A.M.; Abad, J.M.; Takahashi, E.K.; Rosado, A.M.; Faria, D.A.; et al. Genomic Selection for Growth and Wood Quality in Eucalyptus: Capturing the Missing Heritability and Accelerating Breeding for Complex Traits in Forest Trees. New Phytol. 2012, 194, 116-128. [CrossRef] [PubMed]

13. Petrinovic, J.F.; Gélinas, N.; Beaulieu, J. Benefits of Using Genetically Improved White Spruce in Quebec: The Forest Landowner's Viewpoint. For. Chron. 2009, 85, 571-582. [CrossRef]

14. Samure, K.; Given, L.M. Data Saturation. In The SAGE Encyclopedia of Qualitative Research Methods; Given, L.M., Ed.; SAGE Publications Ltd.: Thousand Oaks, CA, USA, 2008; pp. 195-196.

15. Maxwell, S.E.; Delaney, H.D. Designing Experiments and Analyzing Data: A Model Comparison Perspective, 2nd ed.; Lawrence Erlbaum Associates: Mahwah, NJ, USA, 2004.

16. Boopathi, N.M. Success Stories in MAS. In Genetic Mapping and Marker Assisted Selection: Basics, Practice and Benefits; Springer: Tamil Nadu, India, 2013; pp. 187-192.

17. Grattapaglia, D. Perspectives on Genome Mapping and Marker-Assisted Breeding of Eucalypts. South. For. J. For. Sci. 2008, 70, 69-75. [CrossRef]

18. McCouch, S. Diversifying Selection in Plant Breeding. PLoS Biol. 2004, 2, 1507-1512. [CrossRef] [PubMed]

19. Ministry of Forests Lands and Natural Resource Operations. Forest and Range Practices Act-Forest Planning and Practices Regulation. Available online: http://www.bclaws.ca/Recon/document/ID/freeside/14_2004 (accessed on 6 November 2016).

20. Snetsinger, J. Guidance on Tree Species Composition at the Stand and Landscape Level; Ministry of Forests and Range: Fort Fraser, BC, Canada, 2009.

21. Hallman, W.K.; Hebden, W.C.; Cuite, C.L.; Aquino, H.L.; Lang, J.T. Americans and GM Food: Knowledge, Opinion and Interest in 2004; Food Policy Institute: New Brunswick, NJ, USA, 2004.

22. Heuvel, T.; Renes, R.J.; Gremmen, B.; Woerkum, C.; Trijp, H. Consumers' Images Regarding Genomics as a Tomato Breeding Technology: “Maybe It Can Provide a More Tasty Tomato". Euphytica 2008, 159, 207-216. [CrossRef]

23. The Europeans and Biotechnology: Eurobarometer 52.1. Available online: https://ec.europa.eu/research/ pdf/eurobarometer-en.pdf (accessed on 6 November 2016).

24. McHughen, A. Public Perceptions of Biotechnology. Biotechnol. J. 2007, 2, 1105-1111. [CrossRef] [PubMed]

25. Pardo, R.; Midden, C.; Miller, J.D. Attitudes toward Biotechnology in the European Union. J. Biotechnol. 2002, 98, 9-24. [CrossRef]

26. Hall, C. GM Technology in Forestry: Lessons from the GM Food “Debate”. Int. J. Biotechnol. 2007, 95, 436-447. [CrossRef]

27. Research and Knowledge Management Branch. Biotechnology. Available online: www.for.gov.bc.ca/hre/ forgen/projects/biotechnology.htm (accessed on 6 November 2016). 
28. Burke, S.W. Responding to New Trees and to the Issues at Hand: The Insistute of Forest Biotechnology. In Tree Biotechnology in the New Millennium: International Symposium on Ecological and Societal Aspects of Transgenic Plantations; Strauss, S.H., Bradshaw, H.D., Eds.; Oregon State University: Columbia River Gorge, Stevenson, WA, USA, 2001; pp. 62-69.

29. Berg, B.L. Qualitative Research Methods for the Social Sciences, 6th ed.; Pearson Education Allyn \& Bacon: Boston, MA, USA, 2007.

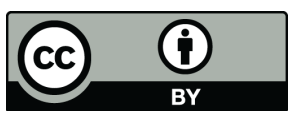

(c) 2016 by the authors; licensee MDPI, Basel, Switzerland. This article is an open access article distributed under the terms and conditions of the Creative Commons Attribution (CC-BY) license (http://creativecommons.org/licenses/by/4.0/). 